\title{
Methodological approach in management and quality sciences
}

\author{
Henryk Dźwigol ${ }^{*}$ \\ ${ }^{1}$ Silesian University of Technology, Faculty of Organisation and Management, Roosevelta 26, 41-800 \\ Zabrze, Poland
}

\begin{abstract}
The article presents methodological approach in management and quality sciences. Quantitative research aims to test hypothesised relationships between variables. Three areas can be identified for assessing the methodological rigour of this type of research: (1) theories relating to phenomena; (2) measures of concepts explaining the phenomena; (3) the reality analysed. it was found that the idiographic approach predominates in the group of theoreticians and represents $59.6 \%$ (239 indications). The nomothetic approach, on the other hand, is used less frequently, accounting for $40.4 \%$ of the responses (162 indications).
\end{abstract}

\section{Introduction}

The mission of management sciences is to provide knowledge and appropriate methods for studying problems in this discipline. The proper selection of methods for the analysed problems is a fundamental methodological issue. Indeed, the foundation of science is not a set of laws or findings, but actually the process of the creation of accumulated knowledge [1].

Methodological evaluation of research can be carried out considering three dimensions [2]:

- conceptual adequacy, which refers to the correctness of embedding the study in the theoretical framework proper to the specific discipline (checking if the appropriate knowledge was applied to define the interesting research problems and if the appropriate methods were selected to solve them),

- methodological rigour, which relates to the project and the research method used (determining whether the research procedure makes it possible to achieve the desired result),

- the empirical material collected to confirm and lend credibility to the results obtained (determining whether the material collected confirms proposed solutions and descriptions and relationships between concepts).

In the economic sciences, rigour is identified with terms such as unambiguity, strictness, or guarantee to achieve a result [3]. This is related to the fact that the result of scientific research should be the gaining of reliable and credible knowledge [4]. However, in the sciences (especially in management sciences), different concepts of truth coexist at the same time. The first of them, the positivist conception of truth, assumes the existence of objective truth, i.e., the existence of regularities, phenomena and laws recognised as independent causal

* Corresponding author: henryk.dzwigol@polsl.pl 
relations. The results of research in this case will be evidenced by the test method of consistency between theoretical predictions and empirical data. Under this approach, a group of criteria for assessing methodological rigour has been determined, oriented towards conformity and referring to the whole sequence: theoretical proposal - measures - results. On the other hand, the interpretative conception of truth assumes the existence of truth through the prism of the social construction of its participants. It is thus hardly repeatable and attributable to specific individuals. The most important criterion for assessing methodological rigour, in this case, is whether the researcher actually reflects the truth as experienced by its participants.

\section{Approach to the status of theory in management sciences}

Within the whole field of economic sciences, a tension can be observed between the rigour of research, treated as formal strictness of built models and their assumptions, and relevance to recipients [3]. On this basis, three types of theory have been specified:

1) very strict,

2) intermediate,

3) of low rigour.

Very rigorous theories are described by the general equilibrium theory. They are based on a few laws and axioms, which are expressed by a mathematical equation, making it possible to prove various economic laws and explain deviations from them. Their weakness, however, is their detachment from reality, lack of empirical evidence and failure to reference assumptions occurring in economic practice $[1,3]$.

Intermediate theories are characterised by game theory, where a mathematical apparatus is proposed to model the relationship between multiple players in different decision-making situations. Unfortunately, in the real-world setting, few people are capable of complex reflection in game theory and, as a result, their behaviours differ from those predicted.

Low rigour theories include all those that are not formally specified through a system of equations. There are few theories of this type in the management sciences, but this does not mean that they are not used to make managerial decisions or explain reality. Hence, it can be concluded that the lack of rigour is not equivalent to limiting the importance of a given theory in management sciences [1].

Given the critical approach to the state of management science theory outlined above, one can see some tension between rigour and relevance. This is because achieving methodological rigour through mathematical modelling meets with fundamental problems, which may include: an issue of the rationality of decision-makers, an impossibility of aggregating individual preferences into a single social preference, or problems concerning profit maximisation. This indicates that there are two groups of recipients of management science theory. On the one hand, these are researchers who aim for high rigour in their research, results obtained and theories built. On the other hand, there are managers and economic practitioners for whom practical usefulness, rather than the degree of rigour in which they have little interest, is crucial. In conclusion, it is necessary to care about research rigour as a way of reaching empirical findings, which, however, does not have to be the same as a mathematical formalisation of a given theory [1].

Quantitative research aims to test hypothesised relationships between variables. Three areas can be identified for assessing the methodological rigour of this type of research:

1) theories relating to phenomena,

2) measures of concepts explaining the phenomena,

3) the reality analysed.

This allows us to postulate models of social processes that include theoretical propositions of causal relationships, an operational relationship of measures that allow the assessment of 
relationships between variables, and a theory that presents causal relationships between variables and measures [5]. Methodological rigour will be associated with each of the areas separately as well as compatibility between them. Compatibility, in this case, determines the basic logic of testing of hypotheses, and reliability is equated with the research characteristic making it possible to achieve comparable results [1].

\section{Validity in research}

Validity, in research, refers to validity of reasoning as well as rightness of an argument. On the other hand, in empirical research, this term is understood as the degree to which a certain research conclusion is an adequate reflection of the truth [6]. In the literature on the subject, many types of validity are indicated; nevertheless, in the management sciences, the internal construct and external validity [7] are the most frequently assessed.

Internal validity is concerned with establishing causal relationships, so this category can only be applied to those studies that analyse the causes of a phenomenon. Causality refers to three requirements [8]:

1) covariance of the statistical relationships analysed,

2) the temporal sequence of data being gathered, i.e., the ability to prove that cause precedes effect,

3) rejection of alternative explanations.

However, it should be noted that in the management sciences, experimental studies are not the predominant methods used. In their framework, internal validity is related to the reference to an appropriate theoretical framework, deductive reasoning, or using specific relationships between variables that allow for an effective defence of results obtained. Moreover, internal validity also increases the value of theoretical triangulation, since multidimensional analysis of a phenomenon influences the selection of the most convincing explanation.

The construct validity is related to the degree to which operationalisation measures a concept which it should measure [9]. Analysis of a multifaceted issue requires a proposal of a concept (construct) that describes a phenomenon under research. However, it should be noted that the opportunity to observe a direct construct occurs very rarely or not at all. Hence, in order to test theoretical propositions, it is necessary to use measures that allow describing the construct in a quantitative way, i.e., to operationalise the construct [1]. However, a strict depiction of the construct requires for a used measure to allow assessing the scale and direction of all features of the construct as well as the construct itself. The most meaningful way of assessing validity of a construct refers to the evaluation of multiple features using multiple measures, which is implemented using the multi-trait multi-method matrix (MTMM) [10]. At least 10 different MTMM matrix analysis procedures are used in the management science literature, which sometimes gives inconsistent results [11]. Nowadays, researchers opt for the factor analysis method because it accurately determines overall level of fit, degree of discriminant and convergent validity, and indicates unambiguous results of variance [1].

External validity is defined by an ability to generalise obtained results over time, in space and taking into account participants in a research. It refers to the extent to which the analysed relationships between variables occur in empirical situations other than those initially assumed. It can be argued that external validity illustrates the background variables that may influence empirical findings [12], and further, that it represents an important indication, for management science researchers and managers, of how likely it is to obtain similar results in other areas [13]. External validity, in discussion about methodological condition of management sciences, is a rarely-discussed issue. On the one hand, it is pointed out that without external validity, the knowledge obtained from conducted research is of little use and 
disproportionate to reality, while on the other hand, the importance of internal validity and construct validity is emphasised, the possible defects of which can be compensated by the size of a sample [14]. However, it is worth emphasising that the possibility of generalisation is affected both by all three types of validity and reliability, and not only by external validity [1]. Reliability refers to repeatability of results obtained in a given study, so it focusses on obtained data before they are used to test for hypotheses. In the literature on the subject, several types of reliability are indicated, considering:
a) time,
b) object of research,
c) performer of research,
d) questions in a research tool [1].

A postulate of repeatability includes an aspiration to confirm the reliability of a test; however, it also results in increasing its costs with an accompanying risk of phenomena lowering the repeatability of results. Hence, tools are selected to analyse the reliability of a test on an existing database and without the need to gather data in it. The most widely recognised tool for assessing reliability is the $\alpha$ coefficient developed by L. Cronbach [15].

Interpretative research is aimed at understanding a studied fragment of reality, i.e., how participants in the studied truth experience it and participate in it, how they shape it and interpret it [16]. There are complex constructs, experienced in different ways by many different actors [17], which opens the field for many possible research approaches based on different experiences. Interpretative research, judged by criterion of whether a procedure actually carried out conforms to canons for a given method, involves four assumptions [18]:

1) collecting and analysing data are interdependent processes and influence each other during research,

2) the basic unit of research is not source data but concept, that is, conceptualisation,

3) concepts are grouped into categories in case they are interrelated and refer to the whole fragment of the phenomenon under study,

4) samples are purposeful and subordinated to theory in order to see particular people in a given area.

The primary criterion for assessing the methodological rigour of qualitative research is credibility [1]. The following criteria for evaluating this type of research are also included [19]:

a) fidelity, i.e., presenting the empirical situation in a way that protects it from the subjectivity of the researcher,

b) transferability, which depends on a rich description of the reality under study and is related to the possibility for other researchers to use results in their analyses,

c) reliability, which refers to purposeful selection of a studied fragment of reality and the method of data collection and data analysis; and

d) confirmability, which is related to data analysis, is strictly conditioned by the time and context of research, and provides an opportunity to obtain similar results by other researchers.

Despite the distinctiveness of qualitative research criteria, in management sciences there is a strong tendency to use criteria taken from the quantitative approach. Two meanings of validity are indicated here [17]: as a result and as a process.

The validity as a result refers not to methods or data, but to narratives, and focusses on the following five aspects [20]:

1) description,

2) interpretation,

3) theory,

4) generalisability,

5) assessment. 
On the other hand, validity as a process takes a form of procedure validation and includes three components: ethics, researcher quality and substance [17].

\section{Selection of methods and research techniques in management and quality sciences}

Conclusions resulting from analysis of domestic and foreign literature on methodology for conducting a research process are reflections on the transformations in management methods occurring over the years, providing an opportunity to explore a condition in which the organisation finds itself. Management methodology is constantly being expanded with new methods characterised by varied cognitive and practical effectiveness. The constant increase in the number of diagnostic instruments is conditioned primarily by changes in environment and is also related to the need to use more and more sophisticated and effective tools. Influence of the practical approach on quality of the research process indicates unequivocally that already at a stage of defining a research problem it is difficult to choose one method giving a possibility of a full and thorough diagnosis of the problem. It is necessary to use diverse research methods providing a comprehensive answer to a problem posed. The very development of heterogeneous cognitive methods, modelling or organisation management implies the necessity of adopting an open approach allowing or even requiring a combination of many approaches and methods. Thanks to conducted research on necessity to diversify research methods in research processes, the degree of using particular methods and techniques or combining them was determined, but also regularities of perceiving the research process were identified in this context as well as other variables, which may influence a relevance of adequate selection of methods and techniques for the research process in management sciences in order to increase credibility, level and quality of conducted research. Moreover, it is pointed out that the use of a number of different methods in the research process allows for a comprehensive approach to a research problem and gives a more complete picture of it [21].

The author proposed constructing a concept of research methodology model using methodological assumptions characterising models, processes or methods for conducting a research process in management sciences in it. Taking into account the achievements of domestic and foreign literature in this field, I have proposed a ten-stage model of the research process including: defining a research gap; defining a research problem; posing theses, hypotheses and research questions; selection of research subjects; selection of research methods and techniques; adopting a research plan; making a measurement; collecting data; data analysis; and generalisation. In proposing the construction of the research methodology, I have included an analysis of selection of methods, impact of combining quantitative and qualitative methods on the research process. Developing good practices in research process in management sciences is difficult and multifaceted and includes:

- Determining research methods to be used in research processes in the management sciences (i.e., observation, interview, documentary analysis, questionnaire and expert group assessment).

- Determining methodological triangulation as a prerequisite in research processes.

- Case study as a method supporting qualitative methods in research processes and providing the possibility of in-depth analysis of a research problem.

- Verification of developed methods, procedures or models in practice in order to make a research effort credible, thus allowing to combine science and management practice.

- The use of pilot studies to guide a research process, being an integral part of it.

- Developing a model, procedure, tool, approach to a research process. 
- Analysis of selected quantitative and qualitative methods for a formulated research problem for their initial selection.

- Results of expert group assessment as a method to verify direction of research conducted.

In my research processes, I use systemic methods and techniques, and qualitative and quantitative methods [22-41]. I pay special attention to the use of triangulation of research methods. Simultaneous application of several research methods is very beneficial for a final result. Then a more comprehensive and reliable presentation of a research problem is obtained, and danger of one-sidedness or even obtaining a result not quite consistent with economic or social reality is avoided $[42,43]$.

There is a necessity to systematise knowledge in the field of methodology of management sciences and to draw researchers' attention to the necessity of combining a number of methods in the research process in order to obtain a comprehensive answer to questions posed. This monograph provides guidance to young researchers beginning their research careers who are struggling with difficulties related to defining a research problem, selecting appropriate methods for solving it, and conducting research. It uses a statistical toolkit that aims to transcribe raw data into a graphical form represented by appropriate models, analyses and other charts. I have managed to identify the laws and rules governing quality and efficiency of a research process in management sciences. The monograph answers several important research questions (RQ), i.e.:

- RQ1. What research methods should be used in research processes in management sciences?

- RQ2. Is methodological triangulation a necessary condition in research processes?

- RQ3. Should qualitative methods in research processes be supported by case studies?

- RQ4. Is it necessary to verify developed methods, procedures or models in practice to make research credible?

- RQ5. Does pilot research orientate a research process?

- RQ6. Is it necessary to develop (model, procedure, tool, approach) for a research process?

The answers to these questions made it possible to conduct relevant research related to development of methods, procedure and model of research process in science and practice of management. Obviously, in order to achieve assumed intentions and realise the main objective, it was necessary to divide it into component parts. Such action made it possible to develop two types of sub-objectives, namely: specific objectives (1. Analysis to select chosen methods in terms of nature of conducted research. 2. Analysis of influence of combining quantitative and qualitative methods on research process. 3. Analysis of influence of pilot studies on research process) and utilitarian (1. Developing [model, procedure, tool, approach] in research process. 2. Developing assumptions for construction of research methodology. 3 . Developing recommendations for the science and practice of management).

In order to conduct research in accordance with generally accepted canons, this thesis had to be accepted: The developed (model, procedure, tool, approach) for selection of methods in a research process has a significant impact on quality and applicability of research results. Before any action can be taken, a plan of action is required to meet all the above-mentioned assumptions and to prevent distortions, misrepresentations and other unforeseen situations from arising. This is achievable when appropriate hypotheses are made. In this case, they are as follows:

1) After formulating a research problem, it is necessary to analyse chosen quantitative and qualitative methods for their initial selection.

2) Pilot studies are an integral part of every research process and guide research process. 
3) Verification of developed methods, models or procedures is a necessary condition for combining the science and practice of management.

4) Methodological triangulation supports research processes in management sciences.

5) Case study provides an opportunity for in-depth analysis of a research problem.

6) Expert group assessment should be the primary method to verify research direction.

7) It is necessary to use two extremely important methods among the methods used in practice for research in management sciences based on observation of facts and classification used in the general methodology of inductive sciences, namely:

- observations carried out in natural conditions, and a researcher interacts with subjects under study,

- observations-interventions that take place within the framework of management activities in the entities surveyed, and the researcher has a direct influence on decisions made.

The research model presented in the figure below was developed in order to obtain answers to hypotheses and research questions posed and to achieve the set objectives. The research model is based on the generally applied procedure [44, 45] including selection of research methods and research techniques. The described model includes the following steps:

- defining a research gap,

- defining a research problem,

- posing hypotheses and research questions,

- selection of a research subject,

- selection of research methods and techniques,

- adopting a research plan,

- making a measurement,

- data collection,

- data analysis,

- generalisation..

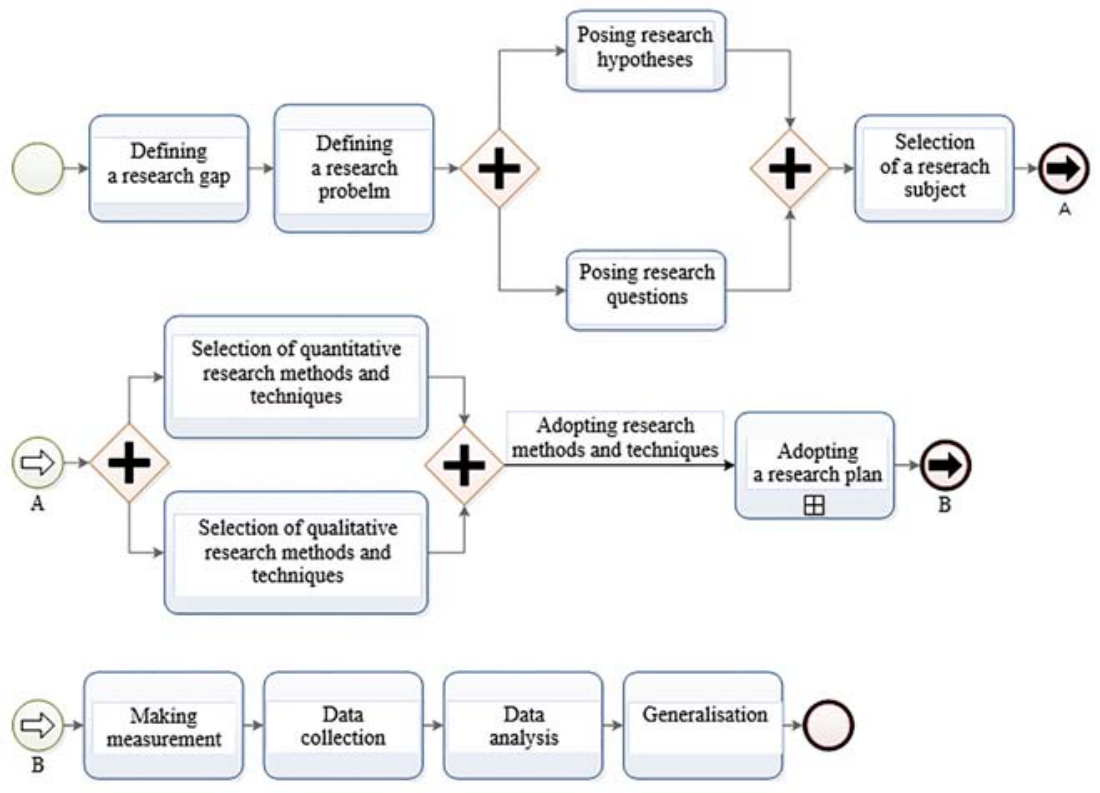

Fig. 1. The research model of the study.

Source: author's own research [21]. 
The synthesis of literature research includes:

- business needs analysis for changes in enterprise needs and therefore the necessity of changes in analytical and diagnostic methods,

- analysis of contemporary trends in the development of management sciences,

- considerations on new trends in management and their transfer to research methodology,

- analysis of selected qualitative and quantitative as well as mixed methods (Figure 1).

Thus, it allows to obtain an answer to the research hypotheses and questions of the study, as well as to achieve the set objectives of the study, to formulate final conclusions, but also to develop a tool for selection of appropriate research methods and techniques for the problem posed (hypothesis, thesis, or research question).

The reliability of the conducted research has also been analysed. The results of the conducted research have been presented here in detail, the comparative analysis of results obtained during the survey of scientists and practitioners in the field of management sciences has been made. The synthesis of literature research includes:

- business needs analysis for changes in enterprise needs and therefore the necessity of changes in analytical and diagnostic methods,

- analysis of contemporary trends in the development of management sciences,

- considerations on new trends in management and their transfer to research methodology,

- analysis of selected qualitative and quantitative as well as mixed methods (Figure 2).

Thus, it allows to obtain an answer to the research hypotheses and questions of the study, to achieve the set objectives of the study, to formulate final conclusions and to develop a tool for selection of appropriate research methods and techniques for the problem posed (hypothesis, thesis, or research question).

\subsection{Appropriate survey}

The survey questionnaire was addressed to academics and practitioners from the field of management sciences. 401 correctly completed questionnaires which form the basis for further analysis were received from the group of scientists, while 196 such questionnaires were received from the group of practitioners.

The quantitative research carried out using the survey questionnaire was addressed to a target group consisting of:

- 272 foreign universities with departments and/or units related to the discipline of management sciences,

- 21024 foreign researchers related to the field of management sciences,

- 93 domestic universities with departments and/or units related to the discipline of management sciences,

- 2307 national researchers related to the field of management sciences,

- 52 foreign enterprises,

- 183 domestic enterprises.

The full listing of the entities surveyed can be found in the Annex.

The research was conducted by means of an anonymous survey questionnaire, which was distributed in hard copy at conferences devoted to issues raised in the discipline of management sciences and electronically as a result of a previously prepared e-mail database.

The research was conducted between October 2016 and April 2018. 


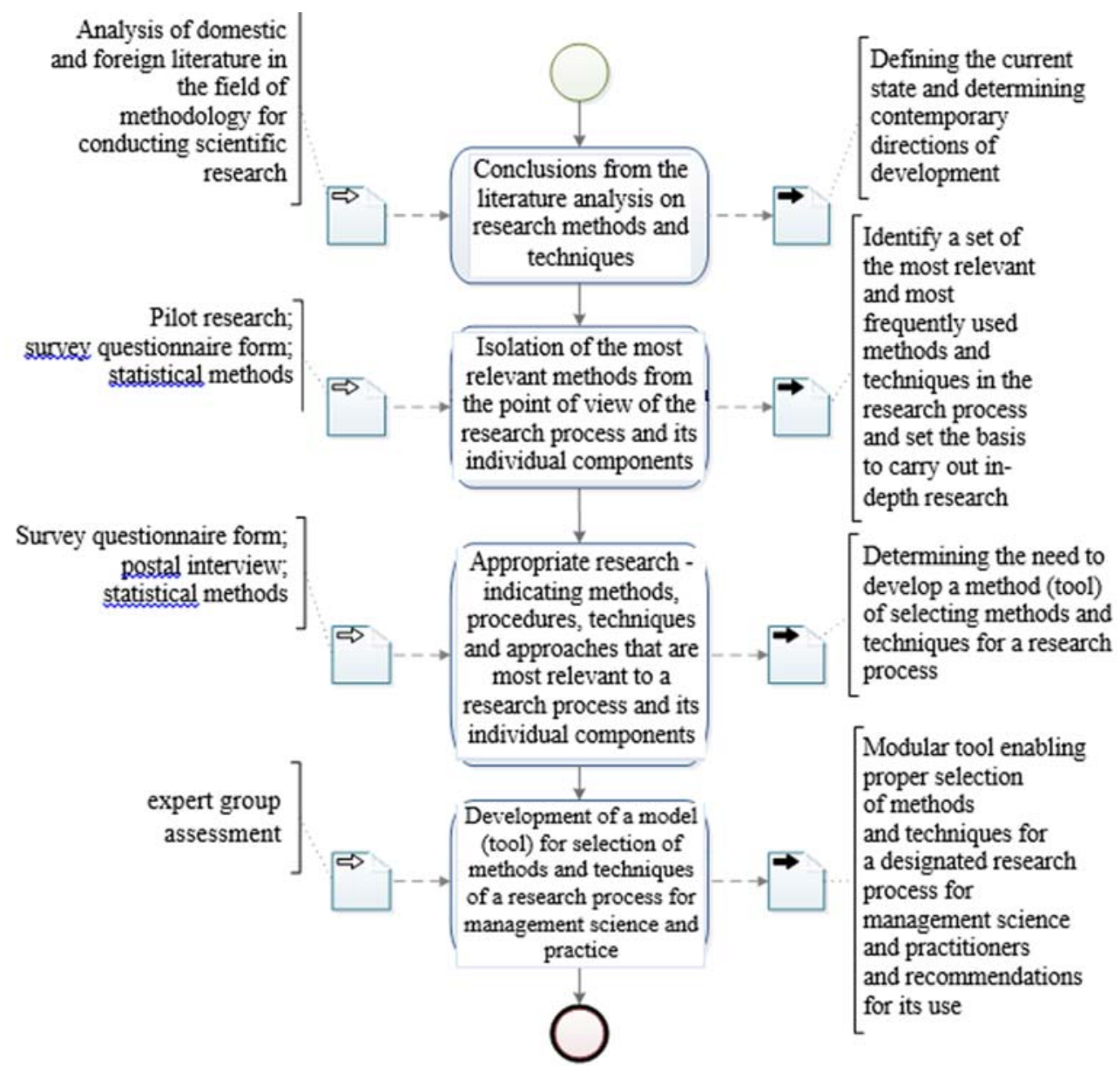

Fig. 2. Process of conducting empirical research.

Source: author's own research [21].

The appropriate survey was conducted on two research groups, for which two separate questionnaires were created. The first research group hereinafter referred to as researchers (theorists) answered 41 questions (including a metrics consisting of 3 questions). The main purpose of the survey for the researchers was to motivate the research problem addressed in this book. The metrics for the researchers specified 3 questions regarding, respectively: place of work, main research area in management sciences, and seniority in university. The responses to the question from the metrics regarding place of work were presented in the pie chart (Figure 3).

In $35 \%$ of cases in total (Poland + abroad) the research group did not indicate the place of work. Foreign universities, which were specified (as to name), constitute $33 \%$, while Polish universities constitute $32 \%$ of the research group.

The results of answers to the second question from the questionnaire metrics are presented in the pie chart below (Figure 4). 


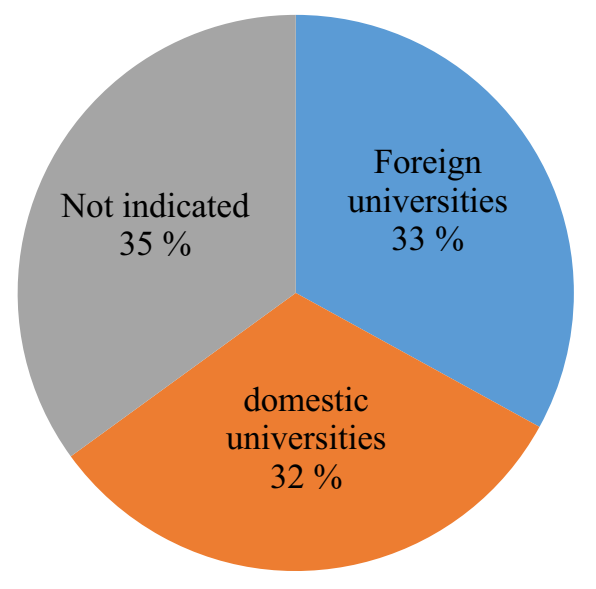

Fig. 3. Participation of individual universities in the group of theorists.

Source: author's own research [21].

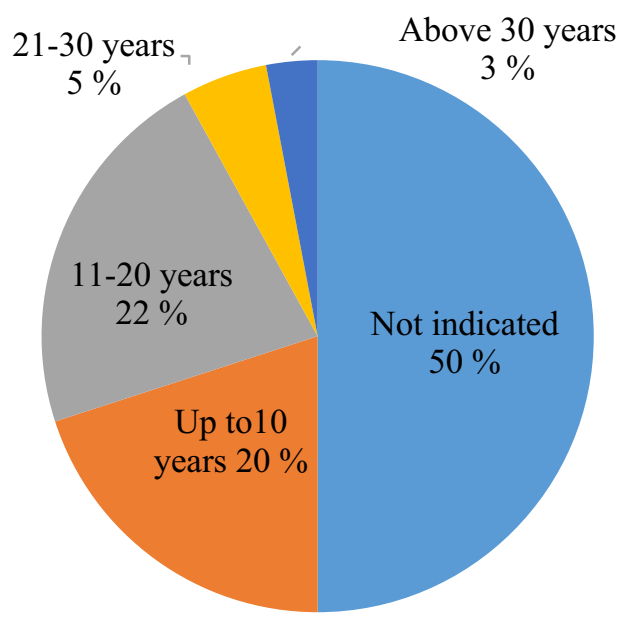

Fig. 4. Percentage structure of seniority of theorists.

Source: author's own research [21].

In $50 \%$ of the cases, job seniority at the university was not indicated. In order of shares, the job seniority specified is as follows: 11-20 years (22\%), up to 10 years (20\%), 21-30 years $(5 \%)$, over 30 years $(3 \%)$.

The range of areas from the research sciences is presented as a summary table (Appendices Research report - theoreticians). The most common areas of research sciences were, among others, strategic management, enterprise management, knowledge management and innovation management, but also organisation research methodology.

The practitioner group accounted for $32.83 \%$ (196/597) of the sample surveyed. The practitioner group included managers from various industries. Questions from the questionnaire metrics for this research group included job seniority, industry (Appendices Research Report - Practitioners), and number of employees employed in an enterprise.

The results of respondents' answers to the question on the length of job seniority are presented in the pie chart below (Figure 5). 


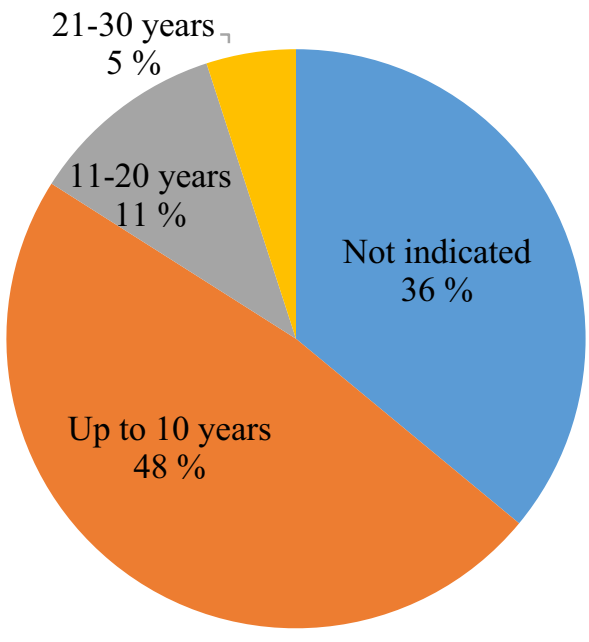

Fig. 5. Percentage structure of job tenure of practitioners.

Source: author's own research [21].

In $36 \%$ of cases practitioners did not indicate their job seniority. The group of practitioners with up to 10 years of job seniority accounted for $48 \%$, while those working between 11 and 20 years accounted for $11 \%$ and 21-30 years accounted for $5 \%$.

The results regarding the number of employees are presented in the pie chart below (Figure 6).

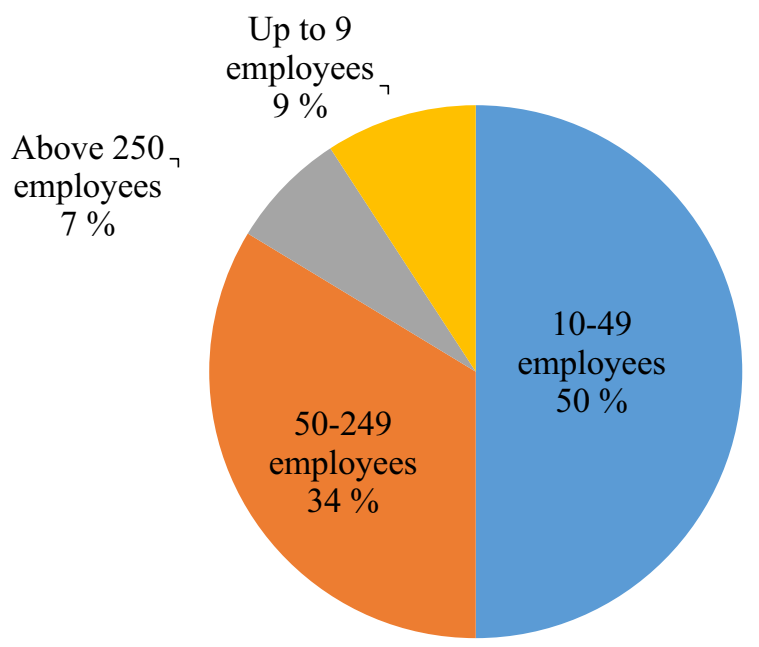

Fig. 6. Structure of the number of employees in an enterprise.

Source: author's own research [21].

$50 \%$ of the practitioners work in an enterprise with between 10 and 49 employees, $34 \%$ between 50 and 249 employees, $9 \%$ with up to 9 employees, while $7 \%$ of the respondents work in an enterprise with more than 250 employees.

The qualitative research conducted using a postal interview was addressed to a target group consisting of independent domestic researchers (27 representatives) and foreign researchers (Ukraine and Romania -5 representatives). 


\section{Research results - researchers}

In the subject undertaken by the author, elements of descriptive statistics will be used to check one of its aspects. This aspect concerns checking the share of research methods and techniques used by the surveyed groups.

\subsection{Analysis of respondents' answers to questions on a qualitative scale in a group of theorists}

The survey questionnaire for the theorists contained questions built on a qualitative scale with different numbers of categories which were treated as text labels for further analysis.

The first question built on the qualitative scale concerned the theorist's choice of the type of methodological approach used in the research. Figure 7 presents the counts of the different answers.

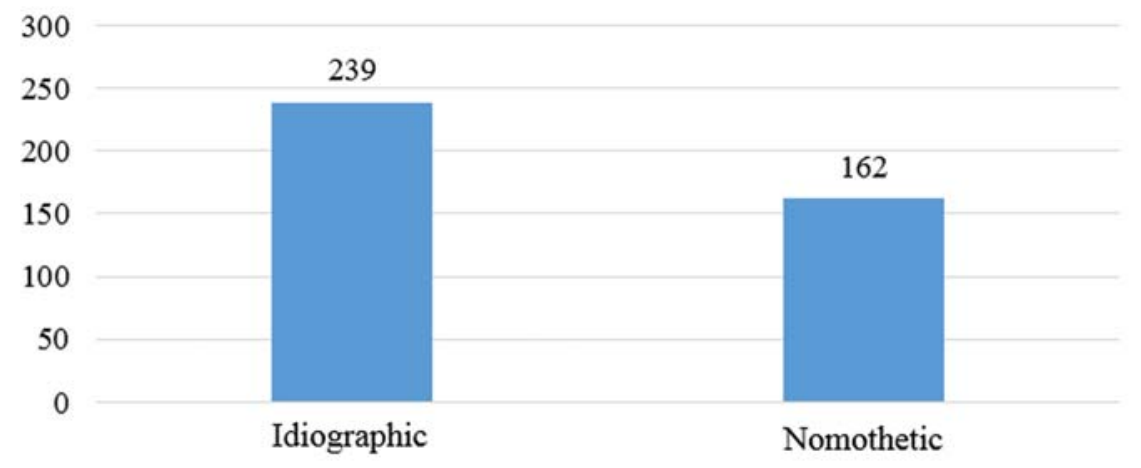

Fig. 7. Methodological approach to research by theorists.

Source: author's own research [21].

On the basis of the chart above, it was found that the idiographic approach predominates in the group of theoreticians and represents $59.6 \%$ (239 indications). The nomothetic approach, on the other hand, is used less frequently, accounting for $40.4 \%$ of the responses (162 indications).

The second question built on the qualitative scale was the question about the types of procedures used. The answers to this question are presented in Figure 8.

It can be seen from the graph that the case study procedure is predominant among the theorists $(36 \%)$, while experiment and correlation take second place $(26 \%)$.

Another multiple-choice question asked to a group of theorists concerned the relevant research methods used in management sciences.

On its basis it was found that in this group the most significant research methods in management sciences are, in order of popularity: observation, interview, documentation analysis, survey, expert group assessment. These 5 methods constitute the set of most frequently used methods.

The next question for this group concerned important research techniques in management sciences. Figure 10 presents the counts of answers of the respondents. 


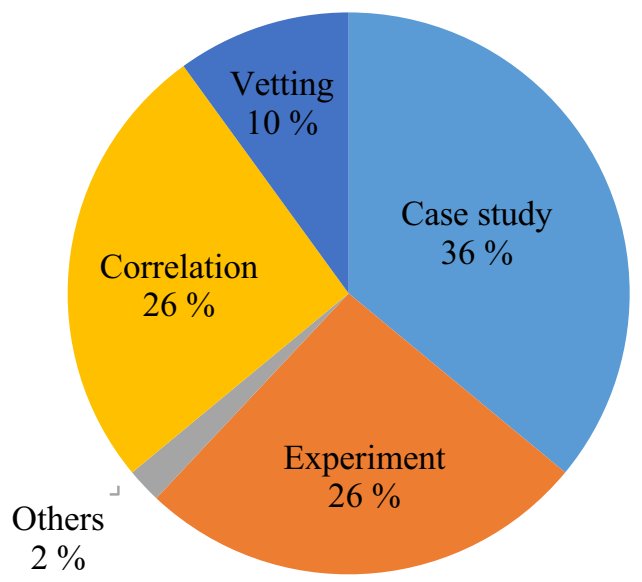

Fig. 8. Procedures used in research by theorists.

Source: author's own research [21].

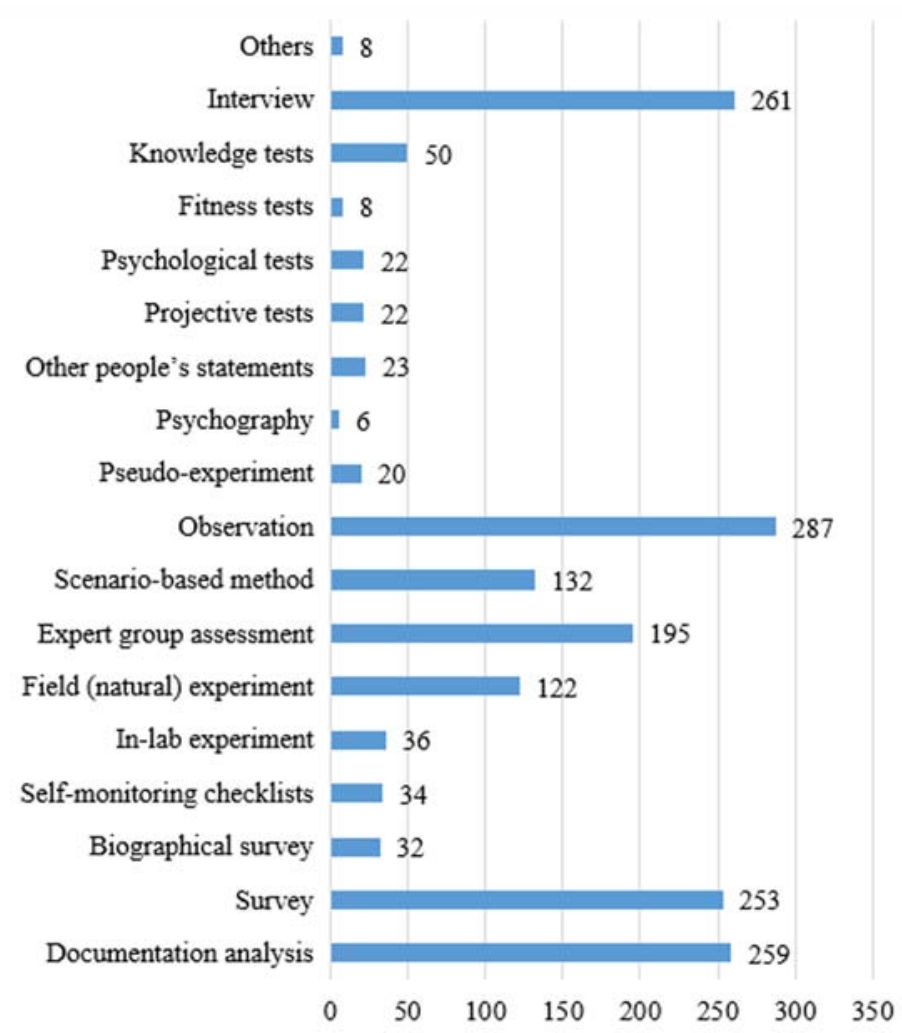

Fig. 9. Research methods used by theorists.

Source: author's own research [21].

On its basis it was found that in this group the most significant research methods in management sciences are, in order of popularity: observation, interview, documentation 
analysis, survey, expert group assessment. These 5 methods constitute the set of most frequently used methods.

The next question for this group concerned important research techniques in management sciences. Figure 10 presents the counts of answers of the respondents.

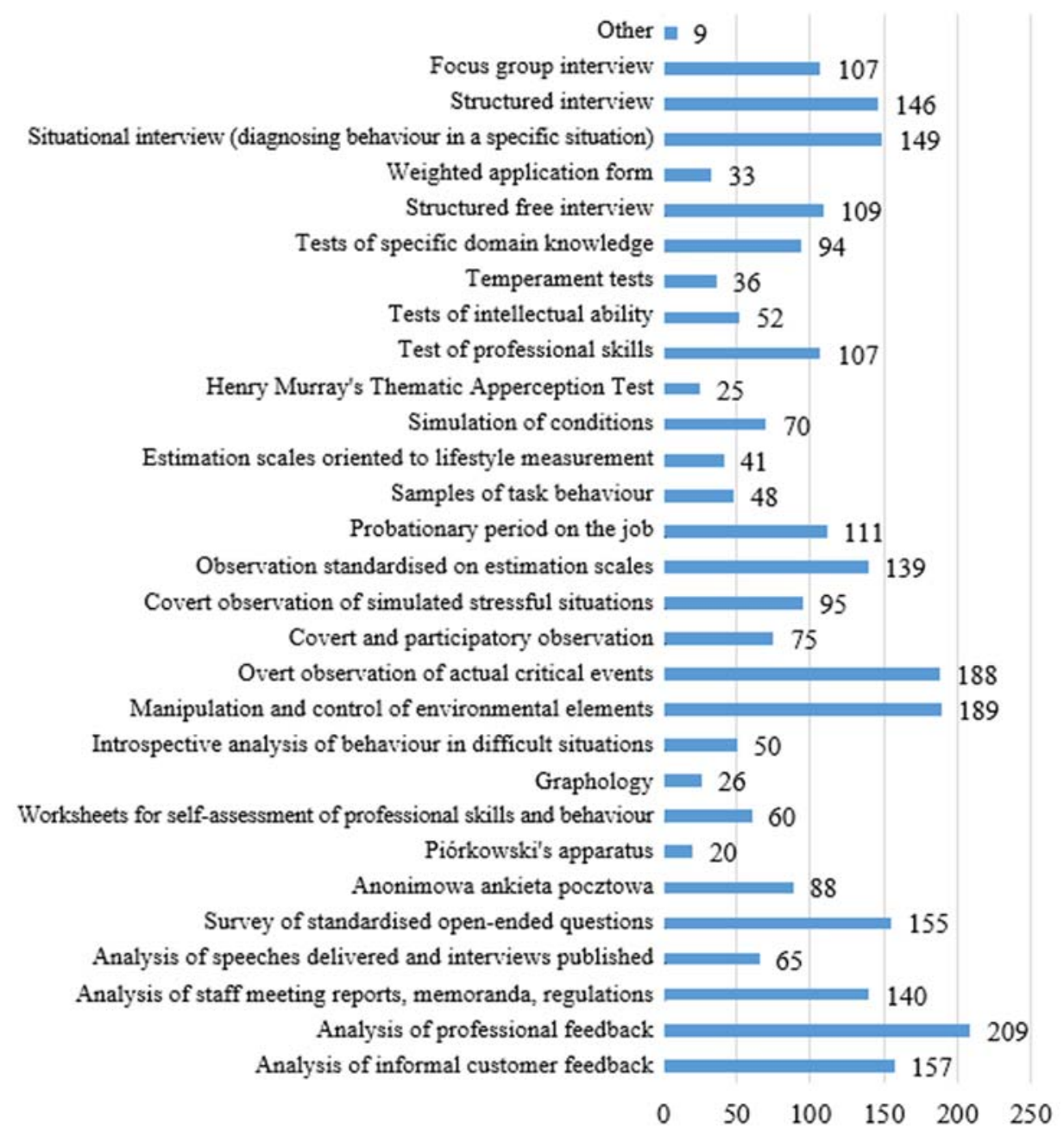

Fig. 10. Research techniques used by theorists.

Source: author's own research [21].

Based on the above chart, it can be concluded that the most commonly used techniques include: analysis of professional feedback, overt observation of real critical, covert and participant observation, analysis of informal customer feedback, survey of standardised open-ended questions, situational interview, structured interview, and analysis of staff meeting reports.

The last qualitative question concerned the applicability of research methods in management sciences. Figure 11 shows the counts. 


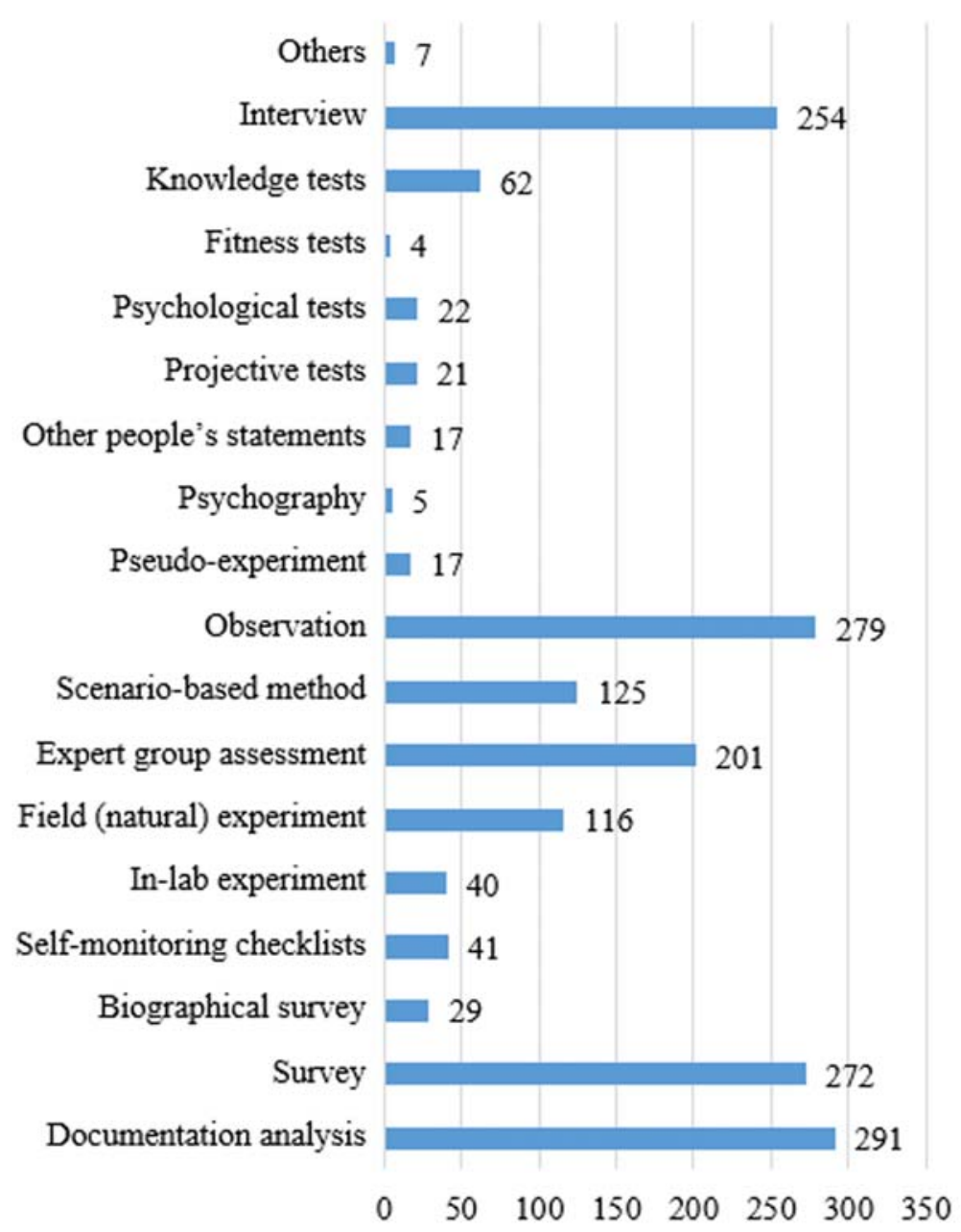

Fig. 11. Research methods used in management sciences.

Source: author's own research [21].

The most commonly used methods are: documentation analysis, observation, survey, interview, expert group assessment.

\section{References}

1. W. Czakon, Rygor metodologiczny, in W. Czakon (ed.), Podstawy metodologii badań w naukach o zarządzaniu (Wydawnictwo Nieoczywiste, Piaseczno, 2016)

2. P. Shrivastava, Strategic Management, Strategic Management Journal, 8(1), 77-92 (1987)

3. M. Blaug, Point, History of Political Economy, 41(2), 219-247 (2009)

4. A. Kieser, L. Leiner, Journal of Management Studies, 46(3), 516-533 (2009)

5. B.K. Boyd, S. Gove, M.A. Hitt, Strategic Management Journal, 26(3), 239-257 (2005) 
6. B.E. Roe, D.R. Just, American Journal of Agricultural Economics, 91(5), 1266-1271 (2009)

7. M. Gibbert, W. Ruigrok, B. Wicki, Strategic Management Journal, 29(13), 1465-1474 (2008)

8. T.A. Scandura, E.A. Williams, Academy of Management Journal, 43(6), 1248-1264 (2000)

9. T.D. Cook, D.T. Campbell, Quasi-Experimentation: Design \& Analysis Issues for Field Settings (Houghton Mifflin, Boston, 1979)

10. D.T. Campbell, D.W. Fiske, Psychological Bulletin, 56(2), 81-105 (1959)

11. R.P. Bagozzi, Y. Yi, Administrative Science Quarterly, 36, 421-458 (1991)

12. B.J. Calder, L.W. Phillips, A.M. Tybout, Journal of Consumer Research, 9(3), 240-244 (1982)

13. J.G. Lynch, Journal of the Academy of Marketing Science, 27(3), 367-376 (1999)

14. J.G. Combs, Academy of Management Journal, 53(1), 9-13 (2010)

15. L.J. Cronbach, Psychometrika, 16(3), 297-334 (1951)

16. P. Johanson, A. Buehring, C. Cassell, G. Symon, International Journal of Management Reviews, 8(3), 131-156 (2006)

17. C.M. Leitch, F.M. Hill, R.T. Harrison, Organizational Research Methods, 13(1), 67-84, (2010)

18. J.M. Corbin, A. Strauss, Qualitative Sociology, 13(1), 3-21 (1990)

19. S.K. Shah, K.G. Corley, BJournal of Management Studies, 43(8), 1821-1835 (2006)

20. J.A. Maxwell, Harvard Educational Review, 62(3), 279-301 (1992)

21. H. Dźwigoł, Współczesne procesy badawcze w naukach o zarządzaniu. Uwarunkowania metodyczne i metodologiczne (PWN, Warszawa, 2018)

22. H. Dźwigoł, Zeszyty Naukowe Politechniki Śląskiej, Organizacja i Zarządzanie, 78, 99-117 (2015)

23. H. Dzwigol, M. Dzwigol-Barosz, R. Miskiewicz, A. Kwilinski, Entrepreneurship and Sustainability Issues, 7(4), 2630-2644 (2020)

24. H. Dzwigol, M. Dzwigol-Barosz, Z. Zhyvko, R. Miskiewicz, H. Pushak, Journal of Security and Sustainability Issues, 8(3), 307-317 (2019)

25. H. Dźwigoł, Virtual Economics, 4(1), 98-117 (2021)

26. H. Dzwigol, Marketing and Management of Innovations, 1, 128-135 (2020)

27. H. Dzwigol, Academy of Strategic Management Journal, 19(4), 1-8 (2020)

28. H. Dzwigol, Marketing and Management of Innovation, 1, 324-335 (2021)

29. H. Dzwigol, R. Wolniak, Przemysl Chemiczny, 97(7), 1114-1116 (2018)

30. H. Dzwigol, M. Dzwigol-Barosz, Academy of Strategic Management Journal, 19(5), 17 (2020)

31. H. Dzwigol, S. Shcherbak, M. Semikina, O. Vinichenko, V. Vasiuta, Academy of Strategic Management Journal, 18(SI1), 1-8 (2019)

32. H. Dzwigol, O. Aleinikova, Y. Umanska, N. Shmygol, Y. Pushak, Journal of Entrepreneurship Education, 22(1S), 1-7 (2019)

33. H. Dzwigol, M. Dźwigot-Barosz, A. Kwilinski, International Journal of Entrepreneurship, 24(1), 1-5 (2020) 
34. Y. Kharazishvili, A. Kwilinski, O. Grishnova, H. Dzwigol, Sustainability, 12(21), 8953 (2020)

35. Y. Kharazishvili, A. Kwilinski, O. Sukhodolia, H. Dzwigol, D. Bobro, J. Kotowicz, Energies, 14(8), 2126 (2021)

36. Y. Kharazishvili, A. Kwilinski, H. Dzwigol, V. Liashenko, Virtual Economics, 4(2), 740 (2021)

37. A. Kwilinski, O. Vyshnevskyi, H. Dzwigol, Journal of Risk and Financial Management, 13(7), 142 (2020)

38. O. Lyulyov, T. Pimonenko, A. Kwilinski, H. Dzwigol, M. Dzwigol-Barosz, V. Pavlyk, P. Barosz, Energies, 14(2), 373 (2021)

39. O. Lyulyov, I. Vakulenko, T. Pimonenko, A. Kwilinski, H. Dzwigol, M. DzwigolBarosz, Energies, 14(12), 3497 (2021)

40. H. Dzwigol, M. Dźwigoł-Barosz, Financial and Credit Activity: Problems of Theory and Practice, 2(25), 424-437 (2018)

41. A. Kwilinski, H. Dzwigol, V. Dementyev, International Journal of Entrepreneurship, 24(1 Special Issue), 1-5 (2020)

42. S. Sudoł, Nauki o zarządzaniu (PWE, Warszawa, 2012)

43. H. Dźwigoł, Zeszyty Naukowe Politechniki Śląskiej, Organizacja i Zarządzanie, 63, 85$111(2013)$

44. C. Frankfort-Nachmias, D. Nachmias, Metody badawcze w naukach społecznych (2001)

45. S. Spałek, Dojrzałość przedsiębiorstwa w zarządzaniu projektami (Wydawnictwo Politechniki Śląskiej, Gliwice, 2013) 